\title{
The use of aortic balloon occlusion in traumatic shock: first report from the $\mathrm{ABO}$ trauma registry
}

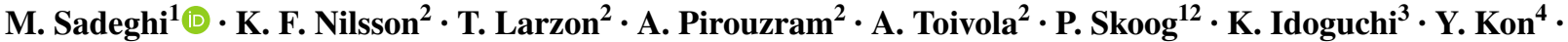

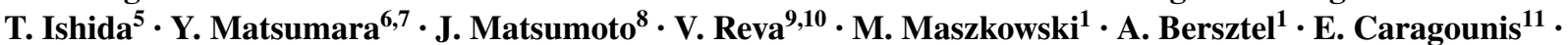 \\ M. Falkenberg ${ }^{13}$ - L. Handolin ${ }^{14}$ • B. Kessel ${ }^{15}$ - D. Hebron ${ }^{15}$. F. Coccolini $^{16}$ • L. Ansaloni ${ }^{16}$ • M. J. Madurska ${ }^{17}$. \\ J. J. Morrison ${ }^{17}$ • T. M. Hörer ${ }^{2}$
}

Received: 7 February 2017 / Accepted: 4 July 2017 / Published online: 11 August 2017

(C) The Author(s) 2017. This article is an open access publication

\begin{abstract}
Purpose Resuscitative endovascular balloon occlusion of the aorta (REBOA) is a technique for temporary stabilization of patients with non-compressible torso hemorrhage. This technique has been increasingly used worldwide during the past decade. Despite the good outcomes of translational studies, clinical studies are divided. The aim of this multicenter-international study was to capture REBOA-specific data and outcomes.

Methods REBOA practicing centers were invited to join this online register, which was established in September 2014. REBOA cases were reported, both retrospective and prospective. Demographics, injury patterns, hemodynamic
\end{abstract}

T. M. Hörer

tal.horer@regionorebrolan.se

1 Västmanlands Hospital Västerås, Department of Vascular Surgery, Örebro University, Örebro, Sweden

2 Department of Cardiothoracic and Vascular Surgery, Faculty of Medicine and Health, Örebro University Hospital, 70185 Örebro, Sweden

3 Senshu Trauma and Critical Care Center, Rinku General Medical Center, Izumisano, Japan

4 Emergency and Critical Care Center, Hachinohe City Hospital, Hachinohe, Japan

5 Emergency and Critical Care Center, Ohta Nishinouchi Hospital, Koriyama, Japan

6 Department of Emergency and Critical Care Medicine, Chiba University Graduate School of Medicine, Chiba, Japan

7 R Adams Cowley Shock Trauma Center, University of Maryland, College Park, MD, USA

8 Department of Emergency and Critical Care Medicine, St Marianna University School of Medicine, Kawasaki, Japan variables, REBOA-specific data, complications and 30-days mortality were reported.

Results Ninety-six cases from 6 different countries were reported between 2011 and 2016. Mean age was $52 \pm 22$ years and $88 \%$ of the cases were blunt trauma with a median injury severity score (ISS) of 41 (IQR 29-50). In the majority of the cases, Zone I REBOA was used. Median systolic blood pressure before balloon inflation was $60 \mathrm{mmHg}$ (IQR 40-80), which increased to $100 \mathrm{mmHg}$ (IQR 80-128) after inflation. Continuous occlusion was applied in $52 \%$ of the patients, and $48 \%$ received non-continuous occlusion. Occlusion time longer than 60 min was reported as 38 and $14 \%$ in the non-continuous and continuous groups, respectively. Complications, such as extremity compartment

9 Department of War Surgery, Kirov Military Medical Academy, Saint Petersburg, Russia

10 Dzhanelidze Research Institute of Emergency Medicine, Saint Petersburg, Russia

11 Sahlgrenska University Hospital, Department of Surgery, University of Gothenburg, Gothenburg, Sweden

12 Department of Vascular Surgery, Örebro University, Örebro, Sweden

13 Department of Radiology, Örebro University, Örebro, Sweden

14 Helsinki University Hospital, Department of Orthopedics and Traumatology, University of Helsinki, Helsinki, Finland

15 Department of Surgery, Hillel Yaffe Medical Centre, Hadera, Israel

16 Department of Surgery, Papa Giovanni XXIII Hospital, Bergamo, Italy

17 Department of Vascular Surgery, Queen Elizabeth University Hospital, Glasgow, UK 
syndrome $(n=3)$, were only noted in the continuous occlusion group. The 30-day mortality for non-continuous REBOA was $48 \%$, and $64 \%$ for continuous occlusion.

Conclusions This observational multicenter study presents results regarding continuous and non-continuous REBOA with favorable outcomes. However, further prospective studies are needed to be able to draw conclusions on morbidity and mortality.

Keywords Aortic occlusion - Trauma - REBOA - IABO . Hemorrhage

$\begin{array}{ll}\text { Abbreviations } \\ \text { NCTH } & \text { Non-compressible torso hemorrhage } \\ \text { DCR } & \text { Damage control resuscitation } \\ \text { REBOA } & \begin{array}{l}\text { Resuscitative endovascular balloon occlusion } \\ \text { of the aorta }\end{array} \\ \text { PRBC } & \text { Packed red blood cells } \\ \text { FFP } & \text { Fresh frozen plasma } \\ \text { PLT } & \text { Platelets } \\ \text { CPR } & \text { Cardiopulmonary resuscitation } \\ \text { GCS } & \text { Glasgow coma scale } \\ \text { SBP } & \text { Systolic blood pressure } \\ \text { ISS } & \text { Injury severity score } \\ \text { ER } & \text { Emergency room } \\ \text { MOF } & \text { Multiple organ failure } \\ \text { MAP } & \text { Mean arterial pressure } \\ \text { pREBOA } & \text { Partial resuscitative endovascular balloon } \\ & \text { occlusion of the aorta } \\ \text { iREBOA } & \text { Intermittent resuscitative endovascular balloon } \\ & \text { occlusion of the aorta } \\ \text { CO } & \text { Continuous occlusion } \\ \text { NCO } & \text { Non-continuous occlusion }\end{array}$

\section{Introduction}

Non-compressible torso hemorrhage $(\mathrm{NCTH})$ is a challenge for trauma clinicians worldwide. Despite advances in the delivery of trauma care, such as damage control resuscitation (DCR) and the formalization of trauma systems, mortality from exsanguination remains as high as $45 \%$ [1]. Hemorrhage control and resuscitation are key management principles; however, these can be difficult to deliver in a timely manner and are often logistically complex.

Resuscitative endovascular balloon occlusion of the aorta (REBOA) is a technique whereby a compliant balloon is temporarily inflated in the aorta, thereby reducing distal blood flow and increasing cardiac afterload [2-4]. This hemodynamic profile is highly advantageous to bleeding patients; thus, REBOA has been proposed as a temporizing adjunct in the management of NCTH until definitive intervention can be achieved $[5,6]$.
However, this is controversial, as REBOA delivery requires specialist training, and balloon deflation can be associated with significant ischemia-reperfusion injury. The current evidence base is weak, with studies showing both good and bad outcomes, although data have often been drawn from registries conceived for different purposes or studies reporting small numbers of cases [7, 8].

In an effort to overcome these shortcomings, the Aortic Balloon Occlusion Trauma Registry (ABO Trauma Registry; www.abotraumaregistry.com) was established in 2014, with the goal of capturing REBOA-specific data from centers using this adjunct across the world. While still in a nascent form, the aim of the current study is to present the initial findings of the registry and patient outcomes.

\section{Methods}

\section{Registry overview}

The ABO Trauma Registry is designed to provide a mechanism for retrospective and prospective data capture for trauma patients in hemorrhagic shock, where management includes the use of REBOA. Center recruitment is ad hoc, with known REBOA-practicing institutions invited to participate directly, but centers can also register independently, via the registry website after approval from the investigators.

To capture clinically pragmatic data, there are no centerspecific criteria, such as minimum case volume or hospital size. The registry is funded and hosted by the Department of Cardiothoracic and Vascular Surgery, Örebro University Hospital, Sweden.

\section{Ethical permission and data security}

Prior to accepting cases, ethical approval was obtained from the regional committee (study number: 2014/210; Uppsala, Sweden). Participating centers also had to obtain approval from their local ethics committee.

Patient data are anonymized at the point of registration with a unique registry-generated ID number; no patient identifiable data, such as date of birth, are held. All data are held on a secure electronic database, and a secured password has been given to centers joining the registry to be able to enter data.

\section{Data collection}

Collection is made via the website and includes data pertaining to demographics, mechanism of injury, vital signs and Glasgow coma scale (GCS) prehospital and on admission, laboratory tests, injury severity score (ISS), systolic blood pressure (SBP) before and after REBOA inflation, REBOA 
and non-REBOA interventions, puncture technique, speciality obtaining access, number of access attempts, zone of occlusion, occlusion time, and resuscitation.

Transfusion size per unit for blood products varies between countries. To be able to calculate the amount of transfusions, units were converted into Swedish transfusion sizes; $300 \mathrm{ml} /$ packed red blood cells (PRBC), $250 \mathrm{ml} /$ fresh frozen plasma (FFP) and $250 \mathrm{ml} /$ platelets (PLT).

Further variable analysis was done on REBOA-specific data related to the length of occlusion, zones of occlusion and the REBOA technique employed. The zones of REBOA occlusion have been defined previously, but in brief: zone I extends from the origin of the left subclavian artery to the celiac trunk, zone II is from the celiac trunk to the lowest renal artery, and zone III involves the infrarenal aorta [3].

REBOA techniques have been defined as continuous (CO) or non-continuous (NCO). A CO technique is described as using a balloon fully inflated from insertion for the entire duration of its use, and only deflated once it is no longer required clinically. This is in contrast to NCO REBOA techniques, which are a heterogeneous group of techniques, such as partial or intermittent inflation. Partial REBOA (pREBOA) is where the balloon volume is reduced to permit a level of flow-through, whereas intermittent occlusion (iREBOA) is where the balloon is deflated entirely at regular intervals [9-12]. Both these techniques have been described as strategies to ameliorate ischemia-reperfusion injury. There is no universally accepted definition of these terms, so we have elected to describe this group as "non-continuous" REBOA techniques to avoid ambiguity.

Complication data were collected in relation to REBOA management, such as balloon migration/rupture, aortic rupture, puncture site hemorrhage, extremity compartment syndrome, and distal embolus, but there are also general complications, such as organ failure. Finally, patient outcome was defined as 30-day mortality.

\section{Data analysis}

Continuous data are presented using mean \pm standard deviation or median and interquartile range (25th-75th percentiles), depending on data distribution. Binary and nominal data are presented using numbers and proportions of available data due to missing information. A simple univariate comparison between survivors and fatalities was made; however, due to anticipated low numbers, multivariate analysis was not planned for this report. Continuous data were compared using a Student $t$ test or Mann-Whitney $U$ test, and categorical data using a Chi squared test. Paired $t$ test and Wilcoxon's test were used for comparison of pre- versus post-REBOA inflation. Significance was set at $p<0.05$. Statistical analysis was completed using IBM SPSS version 23.0 (Armonk, NY, USA).

\section{Results}

\section{Registry overview}

Data were collected retrospectively from November 2011 and prospectively sampled from September 2014 until the end of September 2016. A total of 99 cases were registered: 38 prospective and 61 retrospective from 13 different hospitals within 6 countries (Fig. 1). However, 3 patients were excluded for having not met the inclusion criteria: REBOA was used in non-traumatic shock $(n=1)$, the balloon was not deployed due to access difficulties $(n=1)$, and the balloon was not inflated $(n=1)$. A total of 96 patients remained in the analysis (Table 1).

\section{Patient characteristics, injury patterns and admission physiology}

Sixty-four cases $(67 \%)$ were reported from Japan. The mechanism of injury was blunt trauma in $88 \%$ (84/95) of the patients, and the mean age was $52 \pm 22 \mathrm{yrs}$. Most of the patients (68\%) were males without reported comorbidity (53\%), with a median injury severity score (ISS) of 41 (IQR 29-50) (Table 1). The most common injuries were located in the abdomen (liver, spleen, major abdominal vessels) and pelvis.

Cardiopulmonary resuscitation (CPR) was performed at the injury site in $20 \%$ of the patients (18/91) and was ongoing through to the Emergency room (ER) in 14\% (11/79) of the reported cases. The prehospital GCS score was $>8$ in $63 \%$ (47/75) of the cases, and 40\% (36/91) were reported to have a head injury (Table 1). Pupillary response was absent in 10 out of 37 reported patients, and $90 \%$ of those patients died within 30 days. Intubation was performed in the ER in $64 \%(35 / 55)$ of the patients, and $90 \%$ (86/96) survived the ER (Table 1).

On admission, 66\% (43/65) were in deep hemodynamic shock with a SBP of $<80 \mathrm{mmHg}$. Median SBP before REBOA was $60 \mathrm{mmHg}$ (IQR 40-80), which increased to $100 \mathrm{mmHg}$ (IQR $80-128$ ) immediately after balloon inflation in the hospital. SBP was higher in the survival group compared to the fatalities, before and after inflation $(p<0.05$; Tables 1, 2).

\section{Methods and location of arterial access}

In the majority of the cases $(66 \%, 58 / 88)$, femoral access was achieved in the emergency room, followed by the operating room or the hybrid operating room to the same extents. The puncture method was blind puncture in $84 \%$ of cases (71/85), and was mostly conducted by emergency/intensive care physicians $(67 \%, 60 / 90)$. Access was established on the primary attempt in 55\% (32/58) of the cases. (Table 2). The 
Fig. 1 Location




Table 1 Baseline demography, injury pattern, pre-hospital, ED and laboratory data for the cohorts

\begin{tabular}{|c|c|c|c|c|}
\hline & All & Survivors & Fatalities & $P$ \\
\hline$N$ & 96 & 41 & 55 & \\
\hline \multicolumn{5}{|l|}{ Demography } \\
\hline Age/years $($ total $=84)$ & $52 \pm 22$ & $51 \pm 20$ & $54 \pm 23$ & 0.280 \\
\hline Age $<60$ years $n(\%)($ total $=49)$ & $49(58 \%)$ & $25(64 \%)$ & $24(53 \%)$ & 0.318 \\
\hline Age $>60$ years $n(\%)($ total $=35)$ & $35(42 \%)$ & $14(36 \%)$ & $21(47 \%)$ & \\
\hline Male $/ n(\%)($ total $=96)$ & $65(68 \%)$ & $29(69 \%)$ & $36(67 \%)$ & 0.805 \\
\hline \multicolumn{5}{|l|}{ Pre-morbid health (total $=58$ ) } \\
\hline Co-morbid $n(\%)$ & $27(47 \%)$ & $15(60 \%)$ & $12(36 \%)$ & 0.074 \\
\hline No co-morbidity $n(\%)$ & $31(53 \%)$ & $10(30 \%)$ & $21(64 \%)$ & \\
\hline \multicolumn{5}{|l|}{ Injury mechanism (total = 95) } \\
\hline Blunt $/ n(\%)$ & $84(88 \%)$ & $35(85 \%)$ & $49(91 \%)$ & 0.257 \\
\hline Penetrating/n $(\%)$ & $9(10 \%)$ & $4(10 \%)$ & $5(9 \%)$ & \\
\hline Mixed $/ n(\%)$ & $2(2 \%)$ & $2(5 \%)$ & $0(0 \%)$ & \\
\hline \multicolumn{5}{|l|}{ Injury pattern and location } \\
\hline ISS/median IQR (total = 82) & $41(29-50)$ & $34(20-42)$ & $41(34-51)$ & 0.001 \\
\hline Thorax $/ n(\%)($ total $=96)$ & $25(26 \%)$ & $4(10 \%)$ & $21(39 \%)$ & 0.001 \\
\hline Abdomen $/ n(\%)($ total $=96)$ & $57(59 \%)$ & $26(62 \%)$ & $31(57 \%)$ & 0.656 \\
\hline Pelvis/n $(\%)($ total = 96) & $44(46 \%)$ & $19(45 \%)$ & $25(46 \%)$ & 0.918 \\
\hline Head injury $/ n(\%)($ total $=91)$ & $36(40 \%)$ & $12(30 \%)$ & $24(47 \%)$ & 0.099 \\
\hline \multicolumn{5}{|l|}{ Pre-hospital data } \\
\hline $\mathrm{CPR} / n(\%)($ total $=91)$ & $18(20 \%)$ & $5(13 \%)$ & $13(25 \%)$ & 0.149 \\
\hline $\mathrm{SBP}<80 \mathrm{mmHg} / n(\%)($ total $=50)$ & $29(58 \%)$ & $10(46 \%)$ & $19(68 \%)$ & 0.111 \\
\hline $\mathrm{SBP}>80 \mathrm{mmHg} / n(\%)($ total $=50)$ & $21(42 \%)$ & $12(55 \%)$ & $9(32 \%)$ & \\
\hline GCS $<8 / n(\%)($ total $=75)$ & $28(37 \%)$ & $7(24 \%)$ & $21(46 \%)$ & 0.061 \\
\hline GCS $>8 / n(\%)($ total $=75)$ & $47(63 \%)$ & $22(76 \%)$ & $25(54 \%)$ & \\
\hline \multicolumn{5}{|l|}{ Emergency department data } \\
\hline $\mathrm{CPR} / n(\%)($ total $=79)$ & $11(14 \%)$ & $3(9 \%)$ & $8(18 \%)$ & 0.220 \\
\hline $\mathrm{SBP}<80 \mathrm{mmHg} / n(\%)($ total $=65)$ & $43(66 \%)$ & $19(60 \%)$ & $24(73 \%)$ & 0.255 \\
\hline $\mathrm{SBP}>80 \mathrm{mmHg} / n(\%)($ total $=65)$ & $22(34 \%)$ & $13(41 \%)$ & $9(27 \%)$ & \\
\hline \multicolumn{5}{|l|}{ Laboratory data on admission } \\
\hline $\mathrm{Hb} / \mathrm{g} / \mathrm{L} /$ mean Std (total = 85) & $10.0 \pm 2.4$ & $10.4 \pm 2.3$ & $9.6 \pm 2.5$ & 0.211 \\
\hline $\mathrm{pH} /$ median IQR (total = 76) & $7.20(7.05-7.34)$ & $7.30(7.14-7.39)$ & $7.13(6.99-7.27)$ & 0.001 \\
\hline Base deficit/mean Std (total = 46) & $-11.0 \pm 9.3$ & $-9.0 \pm 5.7$ & $-12.8 \pm 11.6$ & 0.038 \\
\hline Lactate $/ \mathrm{mmol} / \mathrm{l} /$ median IQR $($ total $=45)$ & $8.1(4.3-13.8)$ & $6.6(3.4-9.9)$ & $10.6(5.6-15.0)$ & 0.066 \\
\hline INR/median IQR (total = 51) & $1.3(1.2-1.7)$ & $1.2(1.1-1.4)$ & $1.5(1.3-2.4)$ & 0.001 \\
\hline
\end{tabular}

Categorical data presented as numbers with proportions of cases for each column. Continuous data presented as median (interquartile range) or mean \pm standard deviation depending on the distribution. The total number of reported cases for each variable is presented in parentheses in each row most frequently used sheaths were $7 \operatorname{Fr}(39 \%, 35 / 91)$ mostly used in Japan, followed by 10 and 11 Fr, used frequently in other countries.

\section{REBOA procedure}

Zone I occlusion was used in $94 \%$ of patients (Table 2). Adjustment of the occlusion level was made in $34 \%$ of the 62 reported cases (for different reasons). There were 6 cases where adjustment was made to a different zone, mostly from zone I to III. One adjustment was due to balloon migration.
The rest of the adjustments, 14 cases, were within the same zone.

\section{Methods of definitive hemostasis, resuscitation and critical care}

Thoracotomy was performed in 29 patients of whom 21 underwent aortic clamping, with $86 \%$ mortality. Aortic clamping was performed before REBOA insertion in these cases. Laparotomy was performed in 43 patients, 
Table 2 REBOA specific data

\begin{tabular}{|c|c|c|c|c|}
\hline & All & Survivors & Fatalities & $P$ \\
\hline$n$ & 96 & 41 & 55 & \\
\hline \multicolumn{5}{|l|}{ Location of REBOA (total = 88) } \\
\hline Emergency room/n $(\%)$ & $58(66 \%)$ & $24(63 \%)$ & $34(68 \%)$ & \multirow[t]{5}{*}{0.608} \\
\hline Operating room $/ n(\%)$ & $14(16 \%)$ & $6(16 \%)$ & $8(16 \%)$ & \\
\hline Hybrid operating room $/ n(\%)$ & $14(16 \%)$ & $6(16 \%)$ & $8(16 \%)$ & \\
\hline Intensive care unit $/ n(\%)$ & $1(1 \%)$ & $1(3 \%)$ & 0 & \\
\hline Other $/ n(\%)$ & $1(1 \%)$ & $1(3 \%)$ & 0 & \\
\hline \multicolumn{5}{|l|}{ SBP } \\
\hline SBP before inflation/median IQR (total = 88) & $60(40-80)$ & $70(54-88)$ & $50(0-74)$ & 0.006 \\
\hline SBP after inflation/median IQR (total = 89) & $100(80-128)$ & 111(91-135) & $95(65-125)$ & 0.029 \\
\hline \multicolumn{5}{|l|}{ Puncture technique (total $=85)$} \\
\hline Landmark guided $/ n(\%)$ & $71(84 \%)$ & $34(92 \%)$ & $37(77 \%)$ & \multirow[t]{4}{*}{0.073} \\
\hline Ultrasound guided $/ n(\%)$ & $5(6 \%)$ & $1(3 \%)$ & $4(8 \%)$ & \\
\hline Fluoroscopy guided/n $(\%)$ & $3(3.5 \%)$ & $2(5 \%)$ & $1(2 \%)$ & \\
\hline Cut-down/n $(\%)$ & $6(7 \%)$ & 0 & $6(13 \%)$ & \\
\hline \multicolumn{5}{|l|}{ Specialty obtaining access $($ total $=90)$} \\
\hline $\mathrm{ED} / \mathrm{ICU} / n(\%)$ & $60(67 \%)$ & $29(74 \%)$ & $31(61 \%)$ & \multirow[t]{4}{*}{0.405} \\
\hline Vascular surgeon $/ n(\%)$ & $20(22 \%)$ & $8(21 \%)$ & $12(24 \%)$ & \\
\hline General surgeon/n $(\%)$ & $3(3 \%)$ & 0 & $3(6 \%)$ & \\
\hline Radiologist $/ n(\%)$ & $6(7 \%)$ & $2(5 \%)$ & $4(8 \%)$ & \\
\hline \multicolumn{5}{|l|}{ Attempts at arterial access (total $=58)$} \\
\hline $1 / n(\%)$ & $32(55 \%)$ & $13(54 \%)$ & $19(56 \%)$ & \multirow[t]{3}{*}{0.526} \\
\hline $2-3 / n(\%)$ & $21(36 \%)$ & $10(42 \%)$ & $11(32 \%)$ & \\
\hline$>3 / n(\%)$ & $5(9 \%)$ & $1(4 \%)$ & $4(12 \%)$ & \\
\hline \multicolumn{5}{|l|}{ Zone of occlusion (total = 92) } \\
\hline Zone $1 / n(\%)$ & $86(94 \%)$ & $37(93 \%)$ & $49(94 \%)$ & \multirow[t]{3}{*}{0.674} \\
\hline Zone $2 / n(\%)$ & $3(3 \%)$ & $2(5 \%)$ & $1(2 \%)$ & \\
\hline Zone $3 / n(\%)$ & $3(3 \%)$ & $1(3 \%)$ & $2(4 \%)$ & \\
\hline \multicolumn{5}{|l|}{ Total occlusion time (total $=73)[\mathrm{min} / n(\%)]$} \\
\hline$<30$ & $26(36 \%)$ & $15(48 \%)$ & $11(26 \%)$ & \multirow[t]{3}{*}{0.147} \\
\hline $31-60$ & $26(36 \%)$ & $9(29 \%)$ & $17(41 \%)$ & \\
\hline$>60$ & $21(29 \%)$ & $7(23 \%)$ & $14(33 \%)$ & \\
\hline$<40$ & $38(52 \%)$ & $19(61 \%)$ & $19(45 \%)$ & \multirow[t]{2}{*}{0.175} \\
\hline$>40$ & $35(48 \%)$ & $12(39 \%)$ & $23(55 \%)$ & \\
\hline \multicolumn{5}{|l|}{ Complications } \\
\hline Balloon migration $/ n(\%)($ total $=90)$ & $4(4 \%)$ & $3(8 \%)$ & $1(2 \%)$ & 0.208 \\
\hline Balloon rupture $/ n(\%)($ total $=90)$ & $3(3 \%)$ & $1(3 \%)$ & $2(4 \%)$ & 0.751 \\
\hline Extremity compartment syndrome $/ n(\%)($ total $=42)$ & $3(7 \%)$ & $3(19 \%)$ & 0 & 0.022 \\
\hline Signs of embolization $/ n($ total $=85)$ & $3(4 \%)$ & $1(3 \%)$ & $2(4 \%)$ & 0.657 \\
\hline Aortic/iliac rupture $/ n($ total $=61)$ & 0 & 0 & 0 & \\
\hline Access site bleeding $/ n($ total $=82)$ & 0 & 0 & 0 & \\
\hline
\end{tabular}

embolization in 42, and brain surgery in 15 . No intervention could be made in 9 patients (Table 3 ).

The transfusion requirement for the first $24 \mathrm{~h}$ after REBOA placement shows a median of 7 U PRBC (IQR 3-14, 1 unit PRBC appr 300 ml), 8 U FFP (IQR 4-13, 1 unit FFP appr $250 \mathrm{ml}$ ), and $1 \mathrm{U}$ PLT (IQR 0-2, 1 unit $250 \mathrm{ml}$ ) (Table 3).

\section{Continuous vs. non-continuous occlusion and complications}

The clinician in charge decided whether to use $\mathrm{CO}$ or $\mathrm{NCO}$ REBOA, probably according to the circulatory status of the patient. There were no significant differences between $\mathrm{CO}$ and NCO occlusion groups regarding demography, sex, 
Table 3 Data relating to imaging, modality of definitive hemorrhage control and resuscitation

\begin{tabular}{|c|c|c|c|c|}
\hline & All & Survivors & Fatalities & $P$ \\
\hline$n$ & 96 & 41 & 55 & \\
\hline \multicolumn{5}{|l|}{ Disposal from ED (total = 96) } \\
\hline Operating room $/ n(\%)$ & $25(26 \%)$ & $10(24 \%)$ & $15(28 \%)$ & 0.839 \\
\hline $\mathrm{CT} / n(\%)$ & $10(10 \%)$ & $6(14 \%)$ & $4(7 \%)$ & \\
\hline Angio suite/n (\%) & $4(4 \%)$ & $1(2 \%)$ & $3(6 \%)$ & \\
\hline $\mathrm{ICU} / n(\%)$ & $2(2 \%)$ & $1(2 \%)$ & $1(2 \%)$ & \\
\hline Hybrid operating room $/ n(\%)$ & $12(13 \%)$ & $6(14 \%)$ & $6(11 \%)$ & \\
\hline \multicolumn{5}{|l|}{ Hemorrhage control intervention } \\
\hline Laparotomy $/ n(\%)($ total $=96)$ & $44(46 \%)$ & $23(55 \%)$ & $21(39 \%)$ & 0.122 \\
\hline Thoracotomy $/ n(\%)($ total $=84)$ & $29(35 \%)$ & $3(9 \%)$ & $26(53 \%)$ & $<0.001$ \\
\hline Angioembolization $/ n(\%)($ total $=93)$ & $42(45 \%)$ & $20(48 \%)$ & $22(43 \%)$ & 0.666 \\
\hline Pelvic external-fixation $/ n(\%)($ total $=51)$ & $25(49 \%)$ & $13(54 \%)$ & $12(44 \%)$ & 0.488 \\
\hline Brain surgery $/ n(\%)($ total $=15)$ & $15(100 \%)$ & $3(20 \%)$ & $12(80 \%)$ & \\
\hline No intervention $/ n(\%)($ total $=96)$ & $9(9 \%)$ & $3(7 \%)$ & $6(11 \%)$ & 0.508 \\
\hline \multicolumn{5}{|l|}{ Resuscitation } \\
\hline $\mathrm{PRBC} /$ median IQR $($ total $=81)$ & $7(3-14)$ & $8(4-12)$ & $6(2-14)$ & 0.554 \\
\hline FFP/median IQR (total = 79) & $8(4-13)$ & $8(4-17)$ & $8(4-12)$ & 0.413 \\
\hline PLT/median IQR (total = 74) & $1(0-2)$ & $2(1-2)$ & $1(0-2)$ & 0.052 \\
\hline \multicolumn{5}{|l|}{ ICU care } \\
\hline Days/median IQR (total = 73) & $1(0-5)$ & $5(2-7)$ & $0(0-1)$ & $<0.001$ \\
\hline Multiple organ failure $/ n(\%)($ total $=29)$ & $10(35 \%)$ & $2(18 \%)$ & $8(44 \%)$ & 0.149 \\
\hline \multicolumn{5}{|l|}{ 30-day mortality } \\
\hline$n(\%)($ total $=96)$ & $54(56 \%)$ & 0 & & \\
\hline
\end{tabular}

mechanism of injury, ISS, prehospital GCS or occlusion time (Table 4). However, SBP before inflation and after inflation were higher in the NCO REBOA than in the CO REBOA group ( $p<0.05)$ (Fig. 2).

No major complications, such as bleeding from the REBOA access site or aorta perforation, were reported (Table 2). In the NCO group there were no reported cases with extremity compartment syndrome, but 3 cases were reported in the $\mathrm{CO}$ group. This was due to the sheath placement in 2 of the cases. Balloon migration and balloon rupture were reported in 5 cases in the $\mathrm{NCO}$, and 2 cases in the $\mathrm{CO}$ group. Distal embolization was reported in $2 \mathrm{CO}$ cases and $1 \mathrm{NCO}$ case. There were 2 cases in the $\mathrm{CO}$ group with signs of distal embolization and 1 case in the $\mathrm{NCO}$ group. Multiple organ failure (MOF) was reported in 6 of 18 reported cases in the $\mathrm{CO}$ and 4 of 11 reported cases in NCO group (Table 4).

\section{Mortality}

The median stay at the intensive care units was 5 days (IQR 2-7) for survivors and 0 days (IQR 0-1) for fatalities. The overall 30-day mortality was $56 \%$ (Table 3 ). There was no significant difference regarding mortality between patients older and younger than 60 years (Table 1). The 30-day mortality for the NCO group was $48 \%$, and for the CO group $64 \%$ (Table 4).

\section{Discussion}

The current study presents the initial 24-months experience of a global registry effort to assess the efficacy of aortic balloon occlusion in trauma patients. The registry reports a total of 96 patients recruited. The majority of the reported cases were blunt trauma with high ISS and age with a 30 days mortality of $64 \%$ for $\mathrm{CO}$ and $48 \%$ for NCO patients. This observational report presents interesting data on the management of extra-thoracic hemorrhage and non-compressible torso hemorrhage, and gives is the first registry data on continuous and non-continuous REBOA use.

The current study confirms and extends the findings of the only other published REBOA-specific registry, which is from North America. The prospective observational Aortic Occlusion for Resuscitation in Trauma and Acute Care Surgery (AORTA) demonstrated a mortality among REBOA patients $(n=46)$ of $72 \%$, and among RT patients $(n=68)$ of $84 \%$ [13]. The AORTA registry aims to compare the two existing aortic occlusion techniques (REBOA vs. RT and aortic clamping) in traumatic and acute surgery patients in hemorrhagic shock. There are no prospective multicenter 
Table 4 Comparison of continuous- to non-continuous REBOA

\begin{tabular}{|c|c|c|c|}
\hline & Continuous REBOA & Non-continuous REBOA & $P$ \\
\hline $\mathrm{n}$ & 50 & 46 & \\
\hline \multicolumn{4}{|l|}{ Demography } \\
\hline Male $/ n(\%)($ total $=96)$ & $35(70 \%)$ & $30(65 \%)$ & 0.617 \\
\hline Age/mean Std (total = 84) & $54 \pm 25$ & $51 \pm 18$ & 0.403 \\
\hline \multicolumn{4}{|l|}{ Mechanism of injury (total = 95) } \\
\hline Blunt $/ n(\%)$ & $42(86 \%)$ & $42(91 \%)$ & 0.365 \\
\hline Penetrating/n $(\%)$ & $5(10 \%)$ & $4(9 \%)$ & \\
\hline \multicolumn{4}{|l|}{ ISS } \\
\hline Median (IQR) (total = 82) & $41(30-54)$ & $38(26-50)$ & 0.255 \\
\hline \multicolumn{4}{|l|}{ Occlusion Time (total = 73) $[\mathrm{min} / n(\%)]$} \\
\hline$<30$ & $13(46 \%)$ & $13(29 \%)$ & 0.083 \\
\hline $31-60$ & $11(39 \%)$ & $15(33 \%)$ & \\
\hline$>60$ & $4(14 \%)$ & $17(38 \%)$ & \\
\hline \multicolumn{4}{|l|}{ Pre-hospital data } \\
\hline GCS $<8 / n(\%)($ total $=75)$ & $13(41 \%)$ & $15(35 \%)$ & 0.611 \\
\hline $\mathrm{CPR} / n(\%)($ total $=91)$ & $11(23 \%)$ & $7(16 \%)$ & 0.370 \\
\hline \multicolumn{4}{|l|}{ Systolic blood pressure } \\
\hline ED Admission $<80 \mathrm{mmHg} / n(\%)($ total $=65)$ & $22(67 \%)$ & $21(66 \%)$ & 0.929 \\
\hline SBP mm Hg before inflation/median (IQR) (total = 88) & $50(0-70)$ & $68(43-88)$ & 0.026 \\
\hline SBP mmHg after inflation/median (IQR) (total $=89)$ & $95(69-120)$ & $110(90-135)$ & 0.022 \\
\hline \multicolumn{4}{|l|}{ Laboratory data on admission } \\
\hline ED Lactate/median (IQR) (total = 45) & $8.5(4.2-13.0)$ & $7.4(4.5-13.8)$ & 0.890 \\
\hline ED Base deficit/mean Std (total = 46) & $-11.4 \pm 10.0$ & $-10.3 \pm 8.2$ & 0.426 \\
\hline ED INR/median (IQR) (total = 51) & $1.4(1.2-1.8)$ & $1.2(1.1-1.6)$ & 0.078 \\
\hline \multicolumn{4}{|l|}{ Complications } \\
\hline Extremity compartment syndrome $/ n(\%)($ total $=42)$ & $3(11 \%)$ & 0.0 & 0.180 \\
\hline Balloon migration $/ n(\%)($ total $=90)$ & $1(2 \%)$ & $3(7 \%)$ & 0.285 \\
\hline Balloon rupture $/ n(\%)($ total $=90)$ & $1(2 \%)$ & $2(5 \%)$ & 0.531 \\
\hline Signs of embolization $/ n(\%)($ total $=85)$ & $2(4 \%)$ & $1(3 \%)$ & 0.628 \\
\hline $\mathrm{MOF} / n(\mathrm{MOF} /$ total $)($ total $=29)$ & $6(6 / 18)$ & $4(4 / 11)$ & 0.868 \\
\hline \multicolumn{4}{|l|}{ Mortality } \\
\hline$n(\%)($ total $=96)$ & $32(64 \%)$ & $22(48 \%)$ & 0.111 \\
\hline
\end{tabular}

Fig. 2 Pre- and post-REBOA systolic blood pressures for all patients $(n=88)$, survivals $(n=40)$, fatalities $(n=49)$, continuous-REBOA (COREBOA, $n=44$ ) and noncontinuous-REBOA (NCOREBOA, $n=45$ )

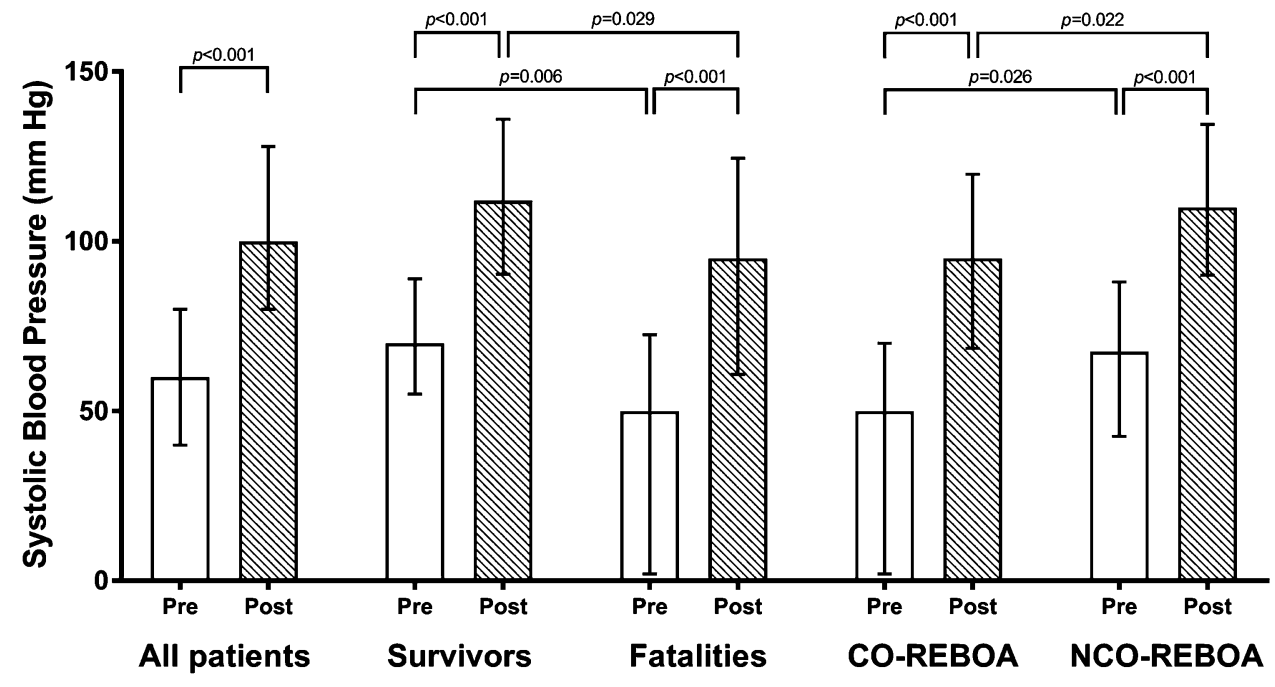


clinical studies with a large collection of patients described so far. The AORTA patients had a median ISS of 31; a majority were injured by a blunt mechanism (62\%); and $60 \%$ were hypotensive (SBP $<90 \mathrm{mmHg}$ ). They are similar to the patients in our cohort but with less blunt trauma (62 vs. $88 \%$ ).

The development and evolution of these registries have been driven by a variety of factors, both experimental and clinical. Translational large-animal studies of REBOA have shown promising results in the management of hemorrhagic shock. REBOA has been shown to increase mean arterial pressure (MAP), decrease the hemorrhage, and reduce the fluid resuscitation volume. Histologic analysis shows a trend toward cardiac and visceral organ damage with occlusion time longer than $60 \mathrm{~min}$ [14-18]. In these studies, no aortic injury $[14,15]$ or necrosis of cerebral or spinal cord has been reported [17].

However, the clinical picture is less clear. The greatest experience worldwide is from Japan, where the Japanese National Trauma Databank (JTDB) has been capturing trauma data, including some REBOA data, for many years. Norii et al. and Inoue et al. have retrospectively compared REBOA and non-REBOA patients regarding mortality $[19,20]$. These studies include a great number of patients (Norii $n=452$ ) (Inoue $n=625$ ) and adjusted the likelihood of receiving REBOA with propensity score analysis to match with non-REBOA patients. The studies conclude that REBOA is associated with higher mortality. Norii et al. calculated a mortality of $76 \%$ in REBOA patients. Inoue et al. reported an in-hospital mortality of $62 \%$ for REBOA versus $45 \%$ for non-REBOA patients.

The findings from these studies are also dependent upon the denominator. A further retrospective paper from Japan by Abe et al. [21] $(n=152)$ demonstrated that REBOA may indeed be superior to RT. The study's endpoint was inhospital mortality, which turned out to be $73 \%$ in REBOA patients and $91 \%$ in RT patients, respectively, similar to the AORTA study's mortality. The authors mention differences in interventions performed in each group and the fact that the REBOA group had less severe thoracic injuries than the patients in the aortic cross-clamping group.

The Japanese studies from the JTDB have collected large cohorts. However, the JTDB is not REBOA or open aortic cross clamping oriented, and therefore lacks specific data related to aortic occlusion. The studies are retrospective and use propensity score matching and analysis to predict outcome after specific exposure. The risk with this methodology is that there are many confounding factors causing difficulty in interpreting the results.

Furthermore, the Japanese experience of the harmful effects of REBOA does not appear to be supported by data from North America and Europe. The clinical series from Gupta et al., Brenner et al. and Hörer et al. [2, 22, 23] have shown good outcomes in both penetrating and blunt trauma patients in hemorrhagic shock. But, despite good results these publications are clinical series with small groups of patients and low levels of evidence, which makes it difficult to reach any solid conclusions based on their observations.

The most interesting part of the current study is the presentation of non-continuous occlusion data. The current study demonstrates a reduced mortality, albeit not statistically significant, in patients treated with partial or intermittent techniques. The non-continuous aortic occlusion techniques show a generally lower mortality rate but also a lower morbidity rate regarding organ failure which is the cause of late deaths occurring in trauma patients [24]. Notably, compartment syndrome only occurred in the $\mathrm{CO}$ group. Theoretically, pREBOA has the effect of ameliorating reperfusion injury. This is potentially a very important finding and further research is required to identify the optimum method for pREBOA.

To date, there are not many clinical studies conducted about partial occlusion, albeit case and technical reports [10, 12]. The translational studies suggest that partial occlusion has the potential of reducing ischemic injuries [11, 25]. The results from non-continuous occlusion in our study should be carefully interpreted since there was a difference between the continuous and non-continuous groups in SBP before inflation of the balloon. In addition, estimation of the degree of the actual partial occlusion requires the possibility of measuring SBP above and below the occlusion site or blood flow distal to the balloon.

The registry faces a number of limitations, which should be discussed. With the current iteration of this registry, the focus has been on REBOA-specific data. Therefore, there is no comparison group to evaluate the efficacy of REBOA use, and there could be selection bias in the reported cases as there are no means for control of inclusion and exclusion of patients. It is also noted that there are missing data for some of the presented parameters. Other identified limitations are differences in indications/policies for REBOA use at each center since there are no defined specifications for its use. A longer follow-up of morbidity and late mortality (3-6 months) is another modification that can be made in future studies.

Some of the shortcomings listed above will be addressed via modifications to the registry in the case of further studies. Equally, a randomized control trial is due to start in the UK in 2017 (the UK-REBOA Trial), which should complement some of the experiences in this early report.

The ABO trauma registry is an effort to gather international data on the current clinical use of REBOA in traumatic shock. The registry gives an insight into international practice from a real-world perspective. Its data collection intends to be ongoing so further centers are encouraged to join and submit data. 
It is important to emphasize that REBOA is an endovascular technique, which requires specific training for its management, and that it is a tool for temporary hemodynamic control until definitive repair. REBOA is therefore part of a trauma management/system, i.e. Endovascular Hybrid Trauma and Bleeding Management (EVTM) and should be used carefully [2]. In several countries, there are REBOA management courses but there are no standardized courses provided yet [26-28]. With the range of specialties involved in this procedure, it is now time to provide structured standardized courses such as the DCR.

\section{Conclusion}

The first 24 months of the ABO registry marks a major achievement in establishing a mechanism for data collection. Further work is required to address some of the limitations identified in this preliminary analysis. However, overall, there is accumulating evidence that REBOA is an effective adjunct in the control of traumatic hemorrhage, and that noncontinuous occlusion could be an alternative in particular cases. This adjunct can be delivered safely by a multi-disciplinary team with a low rate of procedural complications. Further statistical power in the registry is required before comments can be made regarding mortality.

Acknowledgements This study received funding from the Research Committee of Region Örebro County, Nyckelfonden at Örebro University Hospital, ALF Grants (Agreement concerning research and education of doctors), Region Örebro County and Swedish Society for Medical Research. We would like to thank Mr. Jon Kimber for english revision.

\section{Compliance with ethical standards}

Ethical standard All procedures performed in the study involving human participants were in accordance with the ethical standards of the institutional and/or national research committee. Informed consent was not obtained from the individual participants due to the injury patterns and circumstances.

Conflict of interest M Sadeghi, KF Nilsson, T Larzon, A Pirouzram, A Toivola, P Skoog, K Idoguchi, Y Kon, T Ishida, J Matsumoto, V Reva, M Maszkowski, A Bersztel, E Caragounis, M Falkenberg, L Handolin, B Kessel, D Hebron, F Coccolini, L Ansaloni, T Hörer declare that they have no conflict of interest in relation to this work. Y Matsumara is a member of clinical advisory board of Tokai Medical Products. JJ Morrison is a member of the clinical advisory board of Prytime Medical Devices Inc.

Open Access This article is distributed under the terms of the Creative Commons Attribution 4.0 International License (http://creativecommons.org/licenses/by/4.0/), which permits unrestricted use, distribution, and reproduction in any medium, provided you give appropriate credit to the original author(s) and the source, provide a link to the Creative Commons license, and indicate if changes were made.

\section{References}

1. Kisat M, Morrison JJ, Hashmi ZG, Efron DT, Rasmussen TE, Haider AH. Epidemiology and outcomes of non-compressible torso hemorrhage. J Surg Res. 2013;184(1):414-21. doi:10.1016/j.jss.2013.05.099.

2. Horer TM, Skoog P, Pirouzram A, Nilsson KF, Larzon T. A small case series of aortic balloon occlusion in trauma: lessons learned from its use in ruptured abdominal aortic aneurysms and a brief review. Eur J Trauma Emerg Surg Off Publ Eur Trauma Soc. 2015. doi:10.1007/s00068-015-0574-0.

3. Stannard A, Eliason JL, Rasmussen TE. Resuscitative endovascular balloon occlusion of the aorta (REBOA) as an adjunct for hemorrhagic shock. J Trauma. 2011;71(6):1869-72. doi:10.1097/TA.0b013e31823fe90c.

4. Biffl WL, Fox CJ, Moore EE. The role of REBOA in the control of exsanguinating torso hemorrhage. J Trauma Acute Care Surg. 2015;78(5):1054-8. doi:10.1097/TA.0000000000000609.

5. Morrison JJ, Ross JD, Rasmussen TE, Midwinter MJ, Jansen JO. Resuscitative endovascular balloon occlusion of the aorta: a gap analysis of severely injured UK combat casualties. Shock. 2014;41(5):388-93. doi:10.1097/SHK.0000000000000136.

6. Saito N, Matsumoto H, Yagi T, Hara Y, Hayashida K, Motomura $\mathrm{T}$, et al. Evaluation of the safety and feasibility of resuscitative endovascular balloon occlusion of the aorta. $\mathbf{J}$ Trauma Acute Care Surg. 2015;78(5):897-903. doi:10.1097/ TA.0000000000000614 (discussion 4).

7. Qasim Z, Brenner M, Menaker J, Scalea T. Resuscitative endovascular balloon occlusion of the aorta. Resuscitation. 2015;96:275-9. doi:10.1016/j.resuscitation.2015.09.003.

8. Morrison JJ, Galgon RE, Jansen JO, Cannon JW, Rasmussen TE, Eliason JL. A systematic review of the use of resuscitative endovascular balloon occlusion of the aorta in the management of hemorrhagic shock. J Trauma Acute Care Surg. 2016;80(2):324-34. doi:10.1097/TA.0000000000000913.

9. Morrison JJ, Ross JD, Houston RT, Watson JD, Sokol KK, Rasmussen TE. Use of resuscitative endovascular balloon occlusion of the aorta in a highly lethal model of noncompressible torso hemorrhage. Shock. 2014;41(2):130-7. doi:10.1097/ SHK.0000000000000085.

10. Johnson MA, Neff LP, Williams TK, DuBose JJ, Group ES. Partial resuscitative balloon occlusion of the AORTA (P-REBOA): clinical technique and rationale. J Trauma Acute Care Surg. 2016. doi:10.1097/TA.0000000000001146.

11. Russo RM, Neff LP, Lamb CM, Cannon JW, Galante JM, Clement NF, et al. Partial resuscitative endovascular balloon occlusion of the aorta in a swine model of hemorrhagic shock. J Am Coll Surg. 2016. doi:10.1016/j.jamcollsurg.2016.04.037.

12. Hörer TM, Cajander P, Jans A, Nilsson KF. A case of partial aortic balloon occlusion in an unstable multi-trauma patient. Trauma. 2016;18(2):150-4. doi:10.1177/1460408615624727.

13. DuBose JJ, Scalea TM, Brenner M, Skiada D, Inaba K, Cannon $\mathrm{J}$, et al. The AAST prospective aortic occlusion for resuscitation in trauma and acute care surgery (AORTA) registry: data on contemporary utilization and outcomes of aortic occlusion and resuscitative balloon occlusion of the aorta (REBOA). J Trauma Acute Care Surg. 2016;. doi:10.1097/TA.0000000000001079.

14. White JM, Cannon JW, Stannard A, Markov NP, Spencer JR, Rasmussen TE. Endovascular balloon occlusion of the aorta is superior to resuscitative thoracotomy with aortic clamping in a porcine model of hemorrhagic shock. Surgery. 2011;150(3):400-9. doi:10.1016/j.surg.2011.06.010.

15. Morrison JJ, Percival TJ, Markov NP, Villamaria C, Scott DJ, Saches KA, et al. Aortic balloon occlusion is effective in 
controlling pelvic hemorrhage. J Surg Res. 2012;177(2):341-7. doi:10.1016/j.jss.2012.04.035.

16. Avaro JP, Mardelle V, Roch A, Gil C, de Biasi C, Oliver M, et al. Forty-minute endovascular aortic occlusion increases survival in an experimental model of uncontrolled hemorrhagic shock caused by abdominal trauma. J Trauma. 2011;71(3):720-5. doi:10.1097/ TA.0b013e318221a94a (discussion 5-6).

17. Markov NP, Percival TJ, Morrison JJ, Ross JD, Scott DJ, Spencer JR, et al. Physiologic tolerance of descending thoracic aortic balloon occlusion in a swine model of hemorrhagic shock. Surgery. 2013;153(6):848-56. doi:10.1016/j.surg.2012.12.001.

18. Cruz RJ Jr, Poli de Figueiredo LF, Bras JL. Rocha e Silva M. Effects of intra-aortic balloon occlusion on intestinal perfusion, oxygen metabolism and gastric mucosal PCO2 during experimental hemorrhagic shock. Eur Surg Res. 2004;36(3):172-8. doi: $10.1159 / 000077260$.

19. Norii T, Crandall C, Terasaka Y. Survival of severe blunt trauma patients treated with resuscitative endovascular balloon occlusion of the aorta compared with propensity score-adjusted untreated patients. J Trauma Acute Care Surg. 2015;78(4):721-8. doi:10.1097/TA.0000000000000578.

20. Inoue J, Shiraishi A, Yoshiyuki A, Haruta K, Matsui H, Otomo Y. Resuscitative endovascular balloon occlusion of the aorta might be dangerous in patients with severe torso trauma: a propensity score analysis. J Trauma Acute Care Surg. 2016;80(4):559-66. doi:10.1097/TA.0000000000000968 (discussion 66-7).

21. Abe T, Uchida M, Nagata I, Saitoh D, Tamiya N. Resuscitative endovascular balloon occlusion of the aorta versus aortic cross clamping among patients with critical trauma: a nationwide cohort study in Japan. Crit Care. 2016;20(1):400. doi:10.1186/ s13054-016-1577-x.
22. Gupta BK, Khaneja SC, Flores L, Eastlick L, Longmore W, Shaf$\tan \mathrm{GW}$. The role of intra-aortic balloon occlusion in penetrating abdominal trauma. J Trauma. 1989;29(6):861-5.

23. Brenner ML, Moore LJ, DuBose JJ, Tyson GH, McNutt MK, Albarado RP, et al. A clinical series of resuscitative endovascular balloon occlusion of the aorta for hemorrhage control and resuscitation. J Trauma Acute Care Surg. 2013;75(3):506-11. doi:10.1097/TA.0b013e31829e5416.

24. Heckbert SR, Vedder NB, Hoffman W, Winn RK, Hudson LD, Jurkovich GJ, et al. Outcome after hemorrhagic shock in trauma patients. J Trauma. 1998;45(3):545-9.

25. Russo RM, Williams TK, Grayson JK, Lamb CM, Cannon JW, Clement NF, et al. Extending the golden hour: partial resuscitative endovascular balloon occlusion of the aorta in a highly lethal swine liver injury model. J Trauma Acute Care Surg. 2016;80(3):372-80. doi:10.1097/TA.0000000000000940.

26. Brenner M, Hoehn M, Pasley J, Dubose J, Stein D, Scalea T. Basic endovascular skills for trauma course: bridging the gap between endovascular techniques and the acute care surgeon. J Trauma Acute Care Surg. 2014;77(2):286-91. doi:10.1097/ TA.0000000000000310.

27. Villamaria CY, Eliason JL, Napolitano LM, Stansfield RB, Spencer JR, Rasmussen TE. Endovascular Skills for Trauma and Resuscitative Surgery (ESTARS) course: curriculum development, content validation, and program assessment. J Trauma Acute Care Surg. 2014;76(4):929-35. doi:10.1097/TA.0000000000000164 (discussion 35-6).

28. Teeter WA, Matsumoto J, Idoguchi K, Kon Y, Orita T, Funabiki $\mathrm{T}$, et al. Smaller introducer sheaths for REBOA may be associated with fewer complications. J Trauma Acute Care Surg. 2016;81(6):1039-45. doi:10.1097/TA.0000000000001143. 